\title{
Disorders of the Expression of the Multichain IL-2 Receptor in HTLV-I-Associated Adult T-Cell Leukemia
}

\author{
T.A. Waldmann
}

\section{A. Introduction}

The activation of $T$ cells requires two sets of signals from cell surface receptors to the nucleus. The first signal is initiated when appropriately processed and presented foreign antigen interacts with the 90-kD polymorphic heterodimeric T-cell surface receptor for the specific antigen. Following the interaction of antigen presented in the context of products of the major histocompatibility locus and interleukin-1 or interleukin- 6 with the antigen receptor, $\mathrm{T}$ cells synthesize interleukin-2 (IL-2) [1, 2]. To exert its biological effect, IL-2 must interact with specific highaffinity membrane receptors. Resting $\mathrm{T}$ cells do not express high-affinity IL-2 receptors, but receptors are rapidly expressed on $T$ cells after activation with an antigen or mitogen [3, 4].

Progress in the analysis of the structure, function, and expression of the human IL-2 receptor was greatly facilitated by the production by Uchiyama et al. [5] of a monoclonal antibody (termed antiTac) that was shown to recognize the human IL-2 receptor [6].

We have utilized the anti-Tac monoclonal antibody and radiolabeled IL-2 in cross-linking studies to: (a) define multiple IL-2-binding peptides that participate in the human receptor for IL-2; (b) molecularly clone cDNAs for the $55-\mathrm{kD}$ peptide of the human IL-2 receptor; (c) determine the immunological events that require the interaction of IL-2 with its receptor; (d) analyze disorders of IL-2

The Metabolism Branch, National Cancer Institute, National Institutes of Health, Bethesda, Maryland 20892, USA receptor expression in leukemia, especially those forms of leukemia associated with the retrovirus HTLV-I; and (e) develop protocols for the therapy of patients with IL-2 receptor-expressing adult T-cell leukemia and T-cell-mediated autoimmune disorders, and for individuals receiving organ allografts.

\section{B. Structure of the Multisubunit IL-2 Receptor}

The high-affinity IL-2 receptor consists of multiple distinct IL-2-binding peptides. The IL-2-binding receptor peptide identified by the anti-Tac monoclonal on PHA-activated normal lymphocytes is a $55-\mathrm{kD}$ glycoprotein [6]. We and others have defined a second non-Tac IL-2binding peptide with an $\mathrm{M}_{\mathrm{r}}$ of $68-76 \mathrm{kD}$ (p75) $[7,8]$. Using cross-linking methodology, we demonstrated the $\mathrm{p} 75$ peptide on MLA 144, a gibbon T-cell line that does not express the Tac antigen but manifests a few thousand relatively lowaffinity $\left(K_{\mathrm{d}}=14 \mathrm{n} M\right)$ IL-2-binding sites per cell. The p75 peptide was also identified in addition to the Tac peptide (p55) in cell populations that express both high- and low-affinity receptors. We proposed a multichain model for the highaffinity IL-2 receptor in which an independently existing Tac or p75 peptide would represent low- and intermediateaffinity receptors, respectively, whereas high-affinity receptors would be expressed when both peptides are expressed and associated in a receptor complex [7]. To test this working hypothesis, we fused cell membranes from a low-affinity IL-2binding cell line bearing the Tac peptide 
alone (MT-1) with membranes from a cell line bearing the p75 peptide alone (MLA 144) and generated hybrid membranes bearing high-affinity receptors [9]. These studies support the multichain model for the high-affinity IL-2 receptor [7].

There is evidence suggesting a more complex subunit structure that involves peptides in addition to the p55 and the p75 IL-2-binding peptides. Two monoclonal antibodies, OKT27 and OKT27b, were produced that react with distinct epitopes of a $95-\mathrm{kD}$ peptide. The OKT27b antibody inconsistently coprecipitated the 55-kD Tac peptide as well as the $95-\mathrm{kD}$ peptide [10]. A flow cytometric energy transfer technique was used to demonstrate a close nonrandom proximity between the p55 Tac and 95-kD T27 peptides [10]. In addition, fluorescence photobleaching recovery measurements suggest that the Tac and T27 peptides physically interact in situ in HUT 102 membranes [11]. In independent chemical cross-linking studies with radiolabeled IL-2, Herrmann and Diamantstein [12] and Saragovi and Malek [13] presented evidence for an independent 100 115-kD IL-2-binding peptide in mice associated with the $\mathrm{p} 55-$ and $\mathrm{p} 75-\mathrm{kD}$ chains of the high-affinity form of the IL-2 receptor on mouse T-cell blasts, CTLL-16 cells, and sublines of EL-4 transfected with the gene encoding the p55 peptide. This 100 - to $115-\mathrm{kD}$ peptide was not precipitated by an anti-p55-specific antibody. Taken together, these studies suggest that three IL-2-binding peptides (p55, p75, and p95-115) are associated in the multisubunit high-affinity IL-2 receptor.

The three-dimensional structure of the 133 amino acid lymphokine IL-2 has been defined [14]. These studies, taken in conjunction with studies using sitespecific mutagenesis of IL-2 and monoclonal antibodies directed toward defined regions of IL-2 in neutralization and binding assays $[15,16]$, have aided in the analysis of the structure-function relationships of human IL-2. Furthermore, they have led to the identification of the amino acid residues required for binding to the different IL-2 receptor peptides and for biological activity. IL-2 has an $\alpha$-helical tertiary structure involving six $\alpha$ helices that suggests that certain portions of the molecule form a structural scaffold that underlies the receptor-binding facet of the molecule [14]. A short helical segment (helix A, amino acid residues 11 19 ) is required for biological activity and appears to be involved in binding to the p75 IL-2-binding peptide. The second helix on the structural scaffold helix is an extended loop involving residues 33-56 that form a helix interrupted in the middle by $\mathrm{Pro}^{47}$. These two segments are referred to as B and $\mathrm{B}^{\prime}$. This segment appears to be required for binding to the p55 Tac peptide. An additional $\alpha$ helix E (amino acids 107-113) is also positioned on the binding plane and could theoretically bind the proposed $95-115-\mathrm{kD}$ IL2-binding peptide. However, no extensive studies of this region of IL-2 have been made. Finally, the carboxy terminal residues $121-133$ and two of the three cysteine residues (58 and 105) are required for full biological activity and binding [15].

\section{Lymphocyte Functions That Are Regulated by the Interaction of IL-2 with Its Receptor}

The anti-Tac monoclonal antibody has been used to define those lymphocyte functions that require an interaction of IL-2 with the $55-\mathrm{kD}$ inducible receptor on activated $\mathrm{T}$ - and B-lymphocytes. The addition of anti-Tac to cultures of human peripheral blood mononuclear cells inhibited the proliferation of T-lymphocytes stimulated by soluble antigens and by cell surface antigens (autologous and allogeneic mixed lymphocyte reactions) [17]. Anti-Tac was also shown to inhibit the generation of both cytotoxic and suppressor T-lymphocytes in allogeneic cell cultures, but did not inhibit their action once generated. In contrast to the action 
on $\mathrm{T}$ cells, anti-Tac did not inhibit the IL-2-induced activation of large granular lymphocytes into effective MK and LAK cells. As noted above, large granular lymphocytes express the p 75 but not the 55-kD Tac peptide. Furthermore, upregulation of the expression of Tac mRNA and Tac peptide by IL-2 has been demonstrated for a number of cell types (e.g., large granular lymphocytes, B cells, and resting $\mathrm{T}$ cells), including some that initially express few if any Tac molecules $[18,19]$. The addition of IL-2 to such Tac-negative cells, including large granular lymphocytic leukemia cells, augmented transcription of the Tac gene and induced the expression of the Tac peptide [20]. Neither the IL-2-induced activation of large granular lymphocytes nor the upregulation of Tac gene expression was inhibited by the addition of anti-Tac. These results strongly suggest that the p75 peptide is responsible for IL-2-induced activation of large granular lymphocytes and that the p75 peptide can mediate an IL-2 signal without coexpression of the Tac peptide. Thus, the p75 peptide may play an important role in the IL-2-mediated immune response not only by participating with the Tac peptide in the formation of the highaffinity receptor complex on $\mathrm{T}$ cells but also by contributing to the initial triggering of large granular lymphocyte activation so that these cells become efficient NK and LAK cells.

\section{Disorders of IL-2 Expression in Adult T-Cell Leukemia}

A distinct form of mature T-cell leukemia was defined by Takasuki and coworkers [21] and termed adult T-cell leukemia (ATL). T-cell leukemias, such as ATL, that are caused by HTLV-I, as well as all $T$-cell lines infected with HTLV-I, express large numbers of IL-2 Tac receptor peptides. An analysis of this virus and its protein products suggests a potential mechanism for this association between HTLV-I and IL-2 receptor ex- pression. The complete sequence of HTLV-I has been determined by Seiki and colleagues [22]. In addition to the presence of typical long terminal repeats (LTRs), gag, pol, and env genes, retroviral gene sequences common to other groups of retroviruses, HTLV-I and -II were shown to contain an additional genomic region between env and the $3^{\prime}$ LTR referred to as $\mathrm{pX}$ that encodes at least three peptides of 21,27 , and $40-42 \mathrm{kD}$. Sodroski and colleagues [23] demonstrated that one of these, a $42-\mathrm{kD}$ protein they termed the tat protein, is essential for viral replication. The mRNA for this protein is produced by a double splicing event. The tat protein acts on a 21-bp enhancer-like repeat within the LTR of HTLV-I, stimulating transcription [24, $25]$. This tat protein also appears to play a central role in directly or indirectly increasing the transcription of host genes such as the IL-2 and especially the IL-2 Tac receptor genes involved in T-cell activation and HTLV-I-mediated T-cell leukemogenesis [26-28].

\section{E. IL-2 Receptor as a Target for Therapy in Patients with ATL}

The observation that ATL cells constitutively express large numbers of IL-2 receptors identified by the anti-Tac monoclonal antibody, whereas normal resting cells and their precursors do not, provided the scientific basis for therapeutic trials using agents to eliminate the IL-2 receptor-expressing cells. Such agents could theoretically eliminate Tac-expressing leukemic cells or activated $\mathrm{T}$ cells involved in other disease states while retaining the Tac-negative mature normal $\mathrm{T}$ cells and their precursors that express the full repertoire for $\mathrm{T}$-cell immune responses. The agents that have been used or are being developed include: (a) unmodified anti-Tac monoclonal; (b) toxin (e.g., a chain of ricin toxin, Pseudomonas toxin, truncated Pseudomonas toxin) conjugates of anti-Tac; (c) alphaand beta-emitting isotopes (e.g., bis- 
muth-212 and yttrium-90) chelated to anti-Tac; (d) "humanized" recombinant antibodies that combine the variable or hypervariable domains of mouse antiTac associated with the constant domains of human immunoglobulin kappa light and IgG-1 or IgG-3 heavy chains; and (e) interleukin-2 toxin fusion proteins (e.g., IL-2-truncated Pseudomonas toxin).

We have performed a clinical trial to evaluate the efficacy of intravenously administered anti-Tac monoclonal antibody in the treatment of patients with ATL [29]. None of the ten patients treated suffered any untoward reactions, and only one, a patient with anti-Tac-induced clinical remission, produced antibodies to the anti-Tac monoclonal. Three of the patients had a mixed, partial, or complete remission following anti-Tac therapy. These patients may have represented an early autocrine stage of ATL, wherein the leukemic $T$ cells still require IL-2 for their proliferation. Alternatively, the clinical responses may have been mediated by host cytotoxic cells reacting with the tumor cells bearing the anti-Tac mouse immunoglobulin on their surface.

These therapeutic studies have been extended in vitro by examining the efficacy of toxins coupled to anti-Tac selectively to inhibit protein synthesis and viability of Tac-positive ATL lines. The addition of anti-Tac antibody coupled to Pseudomonas exotoxin inhibited protein synthesis by Tac-expressing HUT 102-B2 cells, but not that by the acute $\mathrm{T}$-cell line MOLT-4, which does not express the Tac antigen [30]. Anti-Tac conjugated with unmodified Pseudomonas toxin (PE) was hepatotoxic. Subsequent functional analysis of deletion mutants of the PE structural gene has shown that the $26-\mathrm{kD}$ domain I of the whole $66-\mathrm{kD}$ PE is responsible for cell recognition; domain II for translocation of the toxin across membranes; and domain III for ADP-ribosylation of elongation factor 2 , the step actually responsible for cell death [31]. A PE molecule from which domain I has been deleted (PE40) has full ADP-ribosy- lating activity but extremely low cellkilling activity because of the loss of the cell recognition domain. Anti-Tac PE40 conjugates retained the capacity of unmodified PE to kill Tac-expressing T cells but were two logs less toxic to Tac-nonexpressing cells.

PE40 was also used in IL-2 PE40 constructs to provide an alternative (lymphokine-mediated) method of delivering PE40 to the surface of IL-2 receptor, Tac-positive, cells [32]. These constructs were effective in inhibiting protein syntheses and in killing IL-2 receptor-expressing cells but not the cells that did not display the cell surface IL-2 receptor.

The action of toxin conjugates of monoclonal antibodies depends on their ability to be internalized by the cell and released into the cytoplasm. Anti-Tac bound to IL-2 receptors on leukemic cells is internalized slowly into coated pits and then endosomic vesicles. Furthermore, the toxin conjugate does not pass easily from the endosome to the cytosol, as required for its action on elongation factor 2 . To circumvent these limitations, an alternative cytotoxic reagent was developed that could be conjugated to antiTac and that was effective when bound to the surface of leukemic cells. It was shown that bismuth-212 $\left({ }^{212} \mathrm{Bi}\right)$, an alpha-emitting radionuclide conjugated to anti-Tac by use of a bifunctional chelate, was well suited for this role [33]. Activity levels of $0.5 \mu \mathrm{Ci}$ or the equivalent of 12 $\mathrm{rad} / \mathrm{ml}$ of alpha radiation targeted by ${ }^{212} \mathrm{Bi}-$ labeled anti-Tac eliminated greater than $98 \%$ of the proliferative capacity of the HUT 102-B2 cells, with only a modest effect on IL-2 receptor-negative lines. This specific cytotoxicity was blocked by excess unlabeled anti-Tac, but not by human IgG. Therefore, ${ }^{212} \mathrm{Bi}-$ labeled antiTac is a potentially effective and specific immunocytotoxic agent for the elimination of IL-2 receptor-positive cells.

In addition to its use in the therapy of patients with ATL, IL-2 receptor-directed therapy is being attempted in other clinical states. Specifically, therapeutic studies have been initiated using mono- 
clonal antibodies directed toward the IL2 receptors expressed on autoreactive $T$ cells of certain patients with autoimmune disorders, on host $T$ cells responding to foreign histocompatibility antigens on organ allografts, and on leukemic $T$ and $\mathrm{B}$ cells.

\section{References}

1. Morgan DA, Ruscetti FW, Gallo RC (1976) Selective in vitro growth of $T$ lymphocytes from normal human bone marrows. Science 193:1007-1008

2. Smith KA (1980) T-cell growth factor. Immunol Rev 51:337-357

3. Robb RJ, Munck A, Smith KA (1981) Tcell growth factor receptors. J Exp Med 154:1455-1474

4. Waldmann TA (1986) The structure, function, and expression of interleukin-2 receptors on normal and malignant $T$ cells. Science 232: 727-732

5. Uchiyama $T$, Broder $S$, Waldmann TA (1981) A monoconal antibody (anti-Tac) reactive with activated and functionally mature human T cells. I. Production of anti-Tac monoclonal antibody and distribution of $\mathrm{Tac}^{+}$cells. J Immunol 126:1393-1397

6. Leonard WJ, Depper JM, Uchiyama T, Smith KA, Waldmann TA, Greene WC (1982) A monoclonal antibody that appears to recognize the receptor for human $T$ cell growth factor; partial characterization of the receptor. Nature 300:267-269

7. Tsudo M, Kozak RW, Goldman CK, Waldmann TA (1986) Demonstration of a new (non-Tac) peptide that binds interleukin-2: a potential participant in a multichain interleukin-2 receptor complex. Proc Natl Acad Sci USA 83:9694-9698

8. Sharon M, Klausner RD, Cullen BR, Chizzonite R, Leonard WJ (1986) Novel interleukin- 2 receptor subunit detected by cross-linking under high-affinity conditions. Science 234:859-863

9. Tsudo M, Kozak RW, Goldman CK, Waldmann TA (1987) Contribution of a p75 interleukin-2 binding peptide to a high affinity interleukin-2 receptor complex. Proc Natl Acad Sci USA 84:42154218

10. Szollosi J, Damjanovich S, Goldman CK, Fulwyler M, Aszalos AA, Goldstein G,
Rao P, Talle MA, Waldmann TA (1987) Flow cytometric resonance energy transfer measurements support the association of a 95-kDa peptide termed T27 with the 55-kDa Tac peptide. Proc Natl Acad Sci USA 84:7246-7251

11. Eddidin M, Aszalos A, Damjanovich S, Waldmann TA (1988) Lateral diffusion measurements give evidence for association of the Tac peptide of the IL-2 receptor with the T27 peptide in the plasma membrane of HUT-102-B2 T cells. J Immunol 141:1206-1210

12. Herrmann F, Diamantstein T (1987) The mouse high affinity IL-2 receptor complex. I. Evidence for a third molecule, the putative $\gamma$-chain associated with the $\alpha$ and/or $\beta$-chain of the receptor. Immunobiology 175:145-158

13. Saragovi H, Malek TR (1987) The murine interleukin-2 receptor: irreversible crosslinking of radiolabeled interleukin-2 to high affinity interleukin-2 receptors reveals a non-covalently associated subunit. J Immunol 139:1918-1926

14. Brandhuber BJ, Boone T, Kenny WC, McKay DB (1987) Three-dimensional structure of interleukin-2. Science 238: 1707-1709

15. Ju G, Collins J, Kimberlee LK, Tsien WH, Chizzonite R, Crowl B, Bhatt R, Kilian PL (1987) Structure-function analysis of human interleukin-2: identification of amino acid residues required for biological activity. J Biol Chem 262:57235731

16. Kuo L, Robb RJ (1986) Structure-function relationship for the IL-2 receptor system. I. Localization of a receptor binding site on IL-2. J Immunol 137:1538-1543

17. Depper JM, Leonard WJ, Waldmann TA, Greene WC (1983) Blockade of the interleukin-2 receptor by anti-Tac antibody: inhibition of human lymphocyte activation. J Immunol 131:690-696

18. Waldmann TA, Goldman CK, Robb RJ, Depper JM, Leonard WJ, Sharrow SO, Bongiovanni KF, Korsmeyer SJ, Greene WC (1984) Expression of interleukin-2 receptors on activated human B cells. J Exp Med 160:1450-1466

19. Reem G, Yeh N-H (1984) Interleukin-2 regulates expression of its receptor and synthesis of gamma interferon by human $T$ lymhocytes. Science 255:429-430

20. Tsudo $M$, Goldman CK, Bongiovanni $\mathrm{KF}$, Chan WC, Winton EF, Yagita $M$, 
Grimm EA, Waldmann TA (1987) The p75 peptide is the receptor for interleukin2 expressed on large granular lymphocytes and is responsible for the interleukin-2 activation of these cells. Proc Natl Acad Sci USA 84:5394-5398

21. Takasuki K, Uchiyama T, Sagawa K, Yodoi J (1977) Adult T cell leukemia in Japan. In: Seno S, Takaku F, Irino S (eds) Topics in hematology. Excerpta Medica, Amsterdam, pp 73-77

22. Seiki M, Hattori S, Hirayama Y, Yoshida M (1983) Human adult T-cell leukemia virus: complete nucleotide sequence of the provirus genome integrated in leukemia cell DNA. Proc Natl Acad Sci USA $80: 3618-3622$

23. Sodroski JG, Rosen CA, Haseltine WA (1984) Trans-acting transcriptional activation of the long terminal repeat of human $\mathrm{T}$ lymphotrophic viruses in infected cells. Science 225:381-385

24. Paskavis H, Felber BK, Parlakis GN (1986) Cis-acting sequences responsible for the transcriptonal activation of human T-cell leukemia virus type I constitute a conditional enhancer. Proc Natl Acad Sci USA 83:6558-6562

25. Shimotohno K, Miwa M, Slamon DJ, Chen ISY, Hoshino H, Takano M, Fujino $M$, Sugimara T (1985) Identification of new gene products coded with $\mathrm{X}$-regions of human T-cell leukemia viruses. Proc Natl Acad Sci USA 82:302-306

26. Inoue J, Seiki M, Taniguchi T, Tsuru S, Yoshida $M$ (1986) Induction of interleukin- 2 receptor gene expression by $\mathrm{p} 40^{\mathrm{x}}$ encoded by human T-cell leukemia virus type I. EMBO J 5:2883-2888

27. Cross SL, Feinberg MD, Wolf JB, Holbrook NJ, Wong-Staal F, Leonard WJ (1987) Regulation of the human inter- leukin- $2 \alpha$ chain promoter: activation of a nonfunctional promoter by the transactivation gene of HTLV-I. Cell 49:47-56

28. Maruyama $M$, Shibuya $H$, Harada $H$, Haitakeyama M, Seiki M, Fujita T, Inoue J, Yoshida M, Taniguchi T (1987) Evidence for aberrant activation of the autocrine loop by HTLV-I encoded $\mathrm{p} 40^{\mathrm{x}}$ and T3-Ti complex triggering. Cell 48:343350

29. Waldmann TA, Goldman CK, Bongiovanni KF, Sharrow SO, Davey MP, Cease KB, Greenberg SJ, Longo D (1988) Therapy of patients with human T-cell lymphotrophic virus I-induced adult T-cell leukemia with anti-Tac, a monoclonal antibody to the receptor for interleukin-2. Blood 72:1805-1816

30. FitzGerald D, Waldmann TA, Willingham MC, Pastan I (1984) Pseudomonas exotoxin-anti-Tac: cell-specific immunotoxin active against cells expressing the human T-cell growth factor receptor. J Clin Invest 74:966-971

31. Huang J, FitzGerald DJT, Adga S, Pastan I (1988) Functional domains of Pseudomonas exotoxin identified by deletion analysis of the gene expressed in $E$. coli. Cell 48:129-136

32. Lorberboum-Galski H, Kozak R, Waldmann TA, Bailon P, FitzGerald D, Pastan I (1988) IL2-PE40 is cytotoxic to cells displaying either the p55 or p75 subunit of the IL-2 receptor. J Biol Chem 263: 18650-18656

33. Kozak RW, Atcher RW, Gansow OA, Friedman AM, Hines JJ, Waldmann TA (1986) Bismuth-212 labeled anti-Tac monoclonal antibody: alpha-particle emitting radionuclides as modalities for radioimmunotherapy. Proc Natl Acad Sci USA $83: 474-478$ 